Thorax (1947), 2, 1.

\title{
SOME SEQUELS OF ABNORMALITY AT THE THORACIC OUTLET*
}

BY

\section{J. R. LEARMONTH \\ Edinburgh}

This paper-on obstruction at the thoracic outlet-deals with the results of anomalies of bone and muscle; first rib, cervical rib, and scaleni. Though thoracic surgeons approach these structures from a different exposure, and with a different end in view, they may be interested in the related types of vascular and nervous disturbance, and may like to compare them with any anomalies they have encountered in their own operative procedures and which were possibly not associated with clinical symptoms.

\section{MORPHOLOGY}

The arrangement of the bones which form the thoracic outlet derives from the typical thoracic segment (Fig. 1). This consists of a central piece or centrum (the body of the vertebra) carrying a dorsal and a ventral hoop of bone. The dorsal hoop (neural arch) provides the laminae and spinous process. The central piece or centrum may be defective as to one half (hemivertebra), producing both scoliosis and absence of one rib, which inevitably alter the architecture of the thoracic outlet on both sides; or it may be fused with adjoining central pieces. The ventral hoop, or haemal arch, is much expanded in the thoracic region. The haemal arch has a double origin, from a dorsal segment of bone, the pleurapophysis, and a ventral segment, the

* An address to the Society of Thoracic Surgeons of Great Britain and Ireland delivered on Nov. 8, 1946, in Edinburgh.

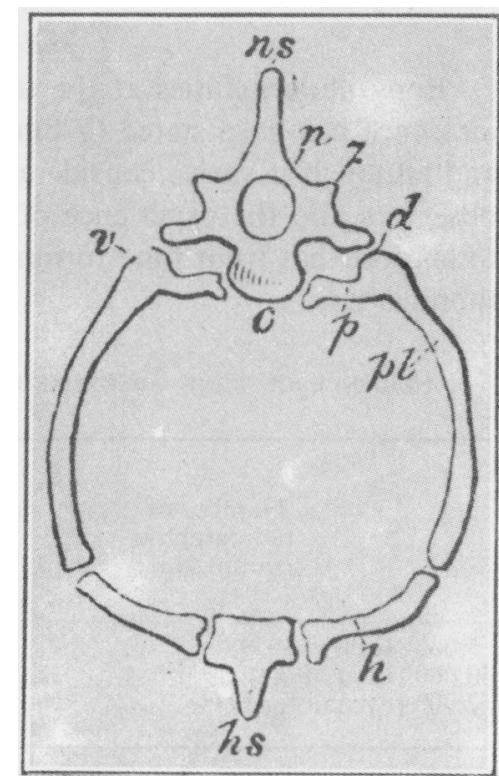

Fig. 1.-Typical thoracic segment (Owen). $C=$ centrum ; $p=$ parapophysis ; $\mathrm{pl}=$ pleurapophysis ; $\mathrm{h}=$ haemapophysis. 


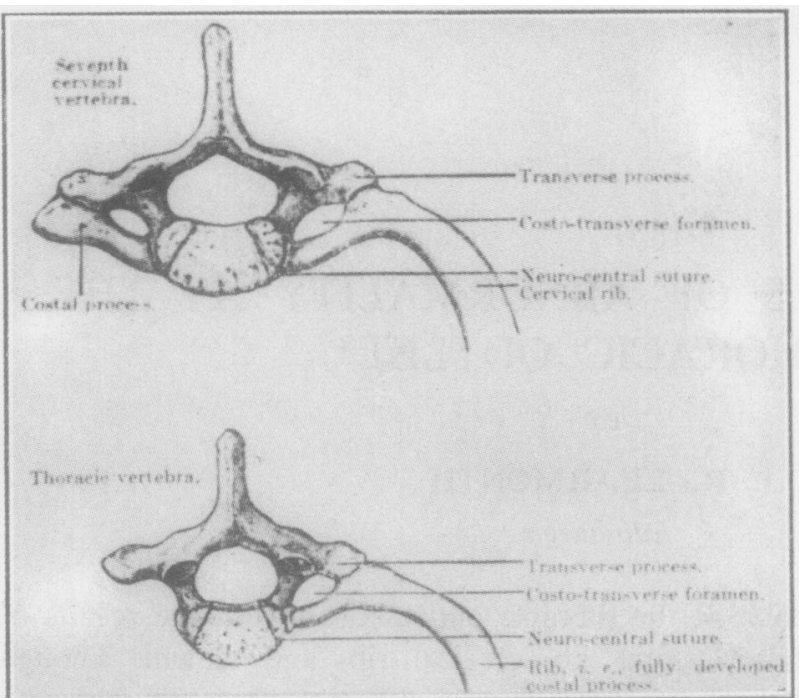

Fig. 2.-Morphological elements of cervical and thoracic vertebrae and ribs in man (Morris).

A.-Osseous anomalies

B.-Muscular anomalies

(1) Cervical rib.

(2) Anomalous first rib.

(3) Scoliosis.

(1) Of scalenus anterior.

(2) Of scalenus pleuralis.

OsSeous ANomalies

haemapophysis ; these two segments ossify separately.

In man, the morphological elements of the vertebral segment can be identified easily (Fig. 2), and certain osseous anomalies of surgical importance can be traced to the persistence of vertebral arrangements more primitive than those reached in the human species. Classification of clinical conditions on an anatomical basis is as follows:

C.-Combined osseous and muscular anomalies

(1) Unusually high first rib.

(2) Costo-clavicular compression.

Bony abnormalities at the thoracic outlet are by no means uncommon. The incidence has been stated (White et al., 1945) for three collected series (Table I), and although it varies considerably from series to series with the interests of the observers and the experience of the radiologists, it is on the whole high enough to suggest that from time to time examples will be encountered in the work of a thoracic unit.

TABLE I

INCIDENCE OF BONY ABNORMALITIES AT THORACIC OUTLET IN 47,000 RADIOGRAPHIC EXAMINATIONS

\begin{tabular}{|c|c|c|c|c|c|c|c|}
\hline \multirow{3}{*}{\multicolumn{4}{|c|}{$\begin{array}{l}\text { Number of } \\
\text { radiographic } \\
\text { examinations }\end{array}$}} & \multicolumn{4}{|c|}{ Incidence of abnormalities } \\
\hline & & & & \multicolumn{2}{|c|}{ Cervical rib } & \multicolumn{2}{|c|}{ First rib } \\
\hline & & & & Number & Percentage & Number & Percentage \\
\hline $\begin{array}{c}5,000 \text { (Haven, 1939) } \\
40,000 \text { (Etter, 1944) } \\
\text { 2,000 (Sycamore, 1944) }\end{array}$ & $\begin{array}{l}\cdots \\
\cdots \\
\cdots\end{array}$ & $\begin{array}{l}\cdots \\
\cdots \\
\cdots\end{array}$ & $\begin{array}{l}\cdots \\
\cdots \\
\cdots\end{array}$ & $\begin{array}{l}37 \\
68 \\
10\end{array}$ & $\begin{array}{l}0.74 \\
0.17 \\
0.5\end{array}$ & $\begin{array}{l}38 \\
31 \\
10\end{array}$ & $\begin{array}{l}0 \cdot 76 \\
0.077 \\
0 \cdot 5\end{array}$ \\
\hline
\end{tabular}

Interest in these bony anomalies is not of recent date: it was first aroused by the biblical account of the creation of Eve, and was one of the "Pseudodoxia" disposed of by Sir Thomas Browne (sixth edition, 1672): 


\section{ABNORMALITY AT THE THORACIC OUTLET}
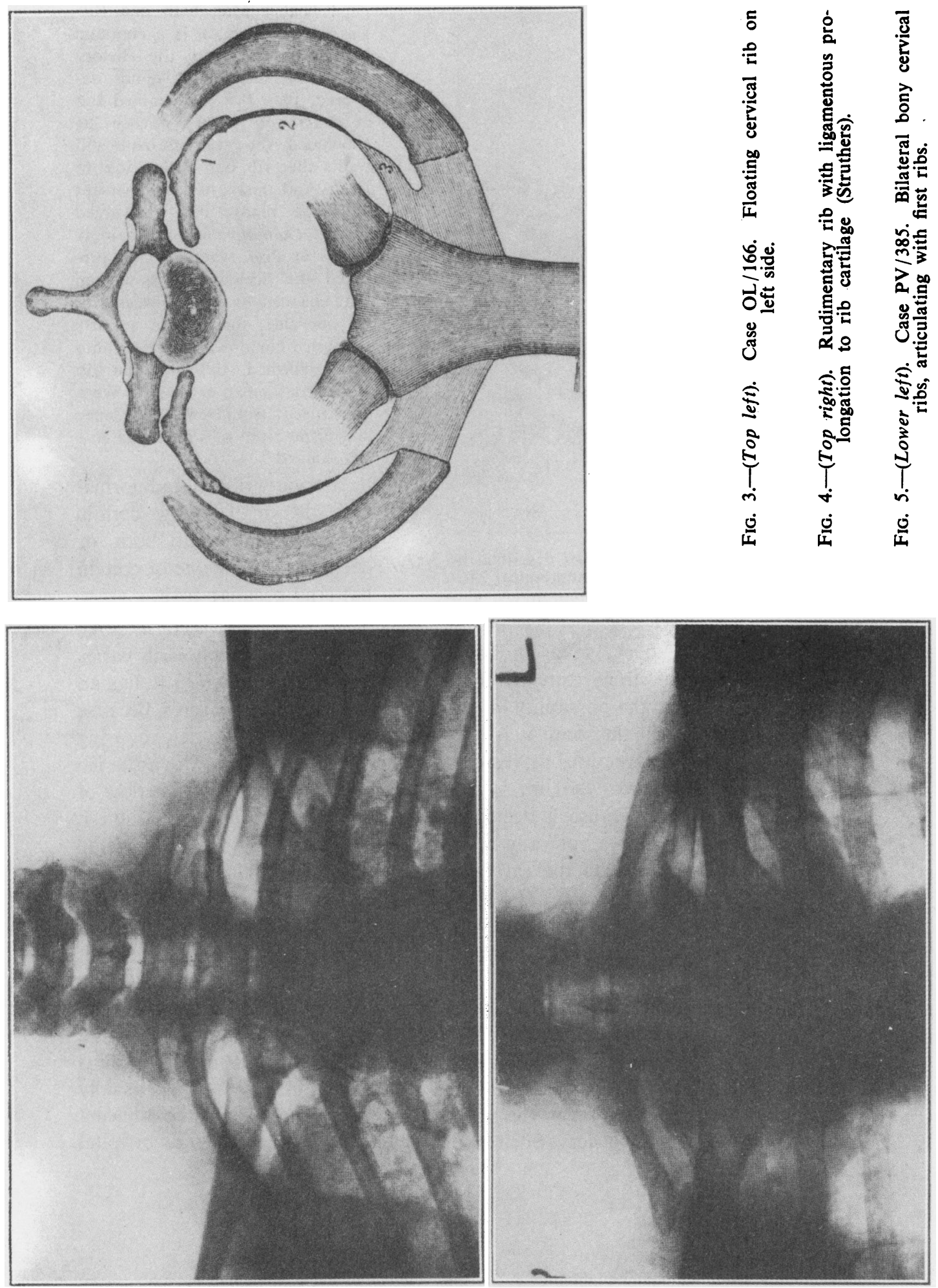

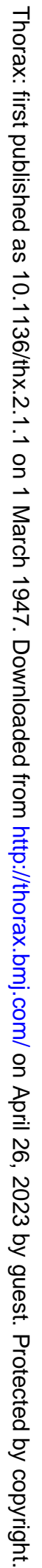



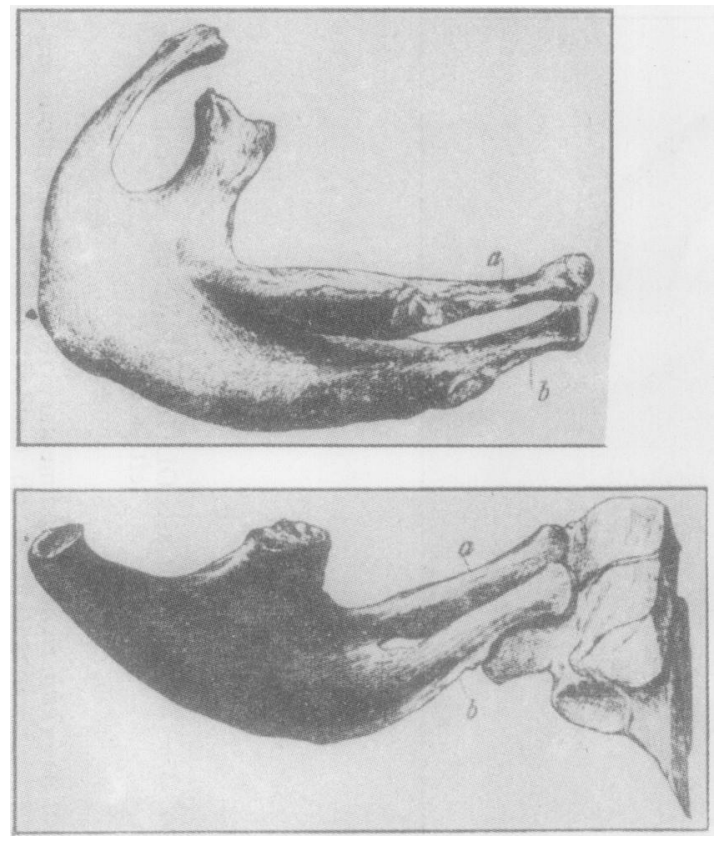

FIG. 6 (A and B).-Bicipital ribs described by Sir William Turner, from the Anatomical Museum of the University of Edinburgh (A, above = specimen $383 \mathrm{a} ; \mathrm{B}$, below $=$ specimen $80 \mathrm{e})$.
"That a Man hath one Rib less then a Woman, is a common conceit derived from the History of Genesis, wherein it stands delivered, that Eve was framed out of a Rib of Adam; whence 'tis concluded the sex of man still wants that rib our Father lost in Eve. And this is not only passant with the many, but was urged against Columbus in an Anatomy of his at Pisa, where having prepared the Sceleton of a woman that chanced to have thirteen ribs on one side, there arose a party that cried him down, and even unto oaths affirmed, this was the rib wherein a woman exceeded. Were this true, it would ocularly silence that dispute out of which side Eve was framed."

Cervical ribs and abnormal first ribs may follow certain patterns common to both, or each may follow one of certain patterns peculiar to it.

1. Common patterns.-An

abnormal rib may "float" (Fig. 3). The movement possible to such a rib varies from almost complete fixity to relatively free mobility; this characteristic has an obvious bearing upon the possibility of the rib producing clinical features, because the more fixed the rib the more it is likely to impinge upon such neighbouring movable and flexible structures as vessels and nerves. The angle at which the rib projects from the related vertebra is also of importance in the production of symptoms and signs, because it decides the anatomical relations of the rib; it varies from a sharp curve ventrally and anteriorly (resembling the abbreviated haemal arch which protects the carotid vessel in birds) to a lateral projection parallel to the transverse process. In other cases, although the bony rib floats, it has a ligamentous prolongation which reaches the sternum or the next (first or second) rib, a condition described by Sir John Struthers, of the University of Aberdeen (Struthers, 1875) (Fig. 4). In still other cases, the ventral end of the intermediate ligamentous strand is ossified where it reaches its ventral attachment.

Other abnormal ribs are bony throughout, but their ventral extremities fai] to reach the sternum, and form either synostoses or more or less movable joints with the next caudal rib (Fig. 5). In the case of cervical ribs, this union is usually in the vicinity of the insertion of the scalenus anterior muscle, or of the adjacent sulcus for the subclavian artery. Such rib-fusions have been described as bicipital 


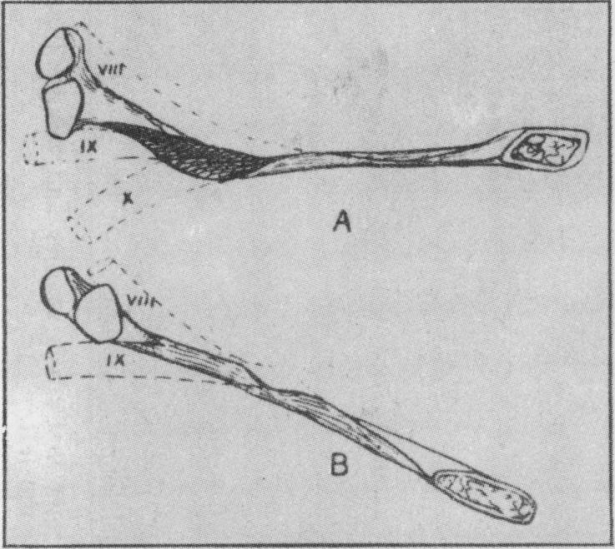

FIG. 7.-A, atypical first thoracic rib, seen from within, to show the bending of the axis of the rib at the site of the sulcus nervi brachialis, contrasted with the corresponding margin of the typical form, B. (Wood Jones). $\quad$ viii $=$ eighth cervical nerve ; ix = first thoracic nerve ; $x=$ second thoracic nerve. (By kind permission of Prof. F. Wood Jones and the Editorial Committee of the Journal of Anatomy.)

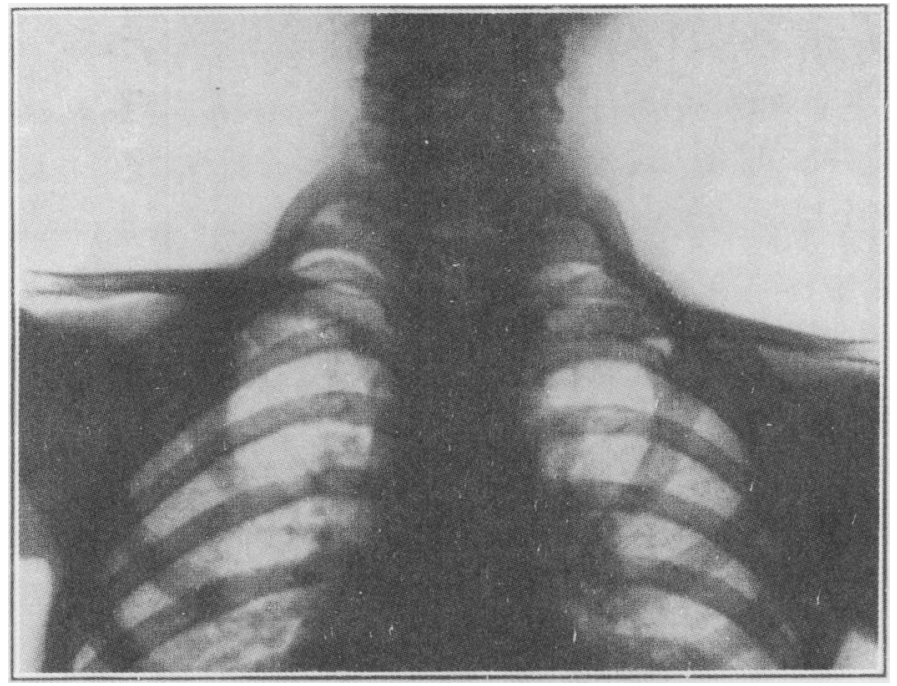

FIG. 8. - Case OL/175. Radiograph of thorax in a case of left subphrenic abscess, to show first and second ribs articulating midway in their arcs on both sides.

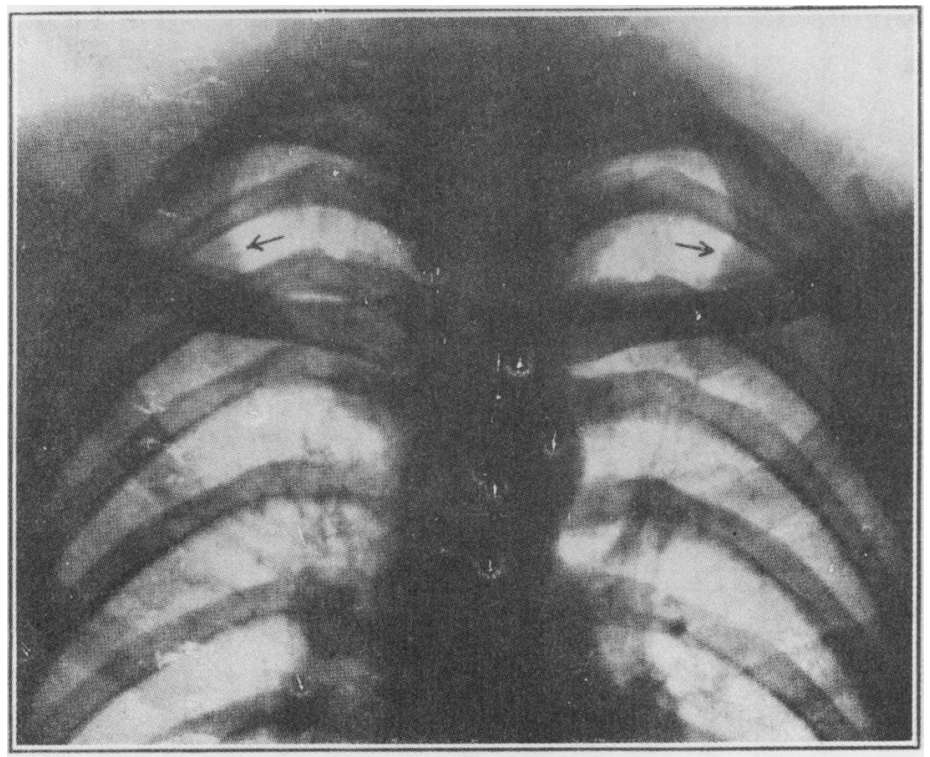

Fig. 9. - Case PV/179. Showing bilateral loss of continuity of first thoracic ribs, of congenital origin. 

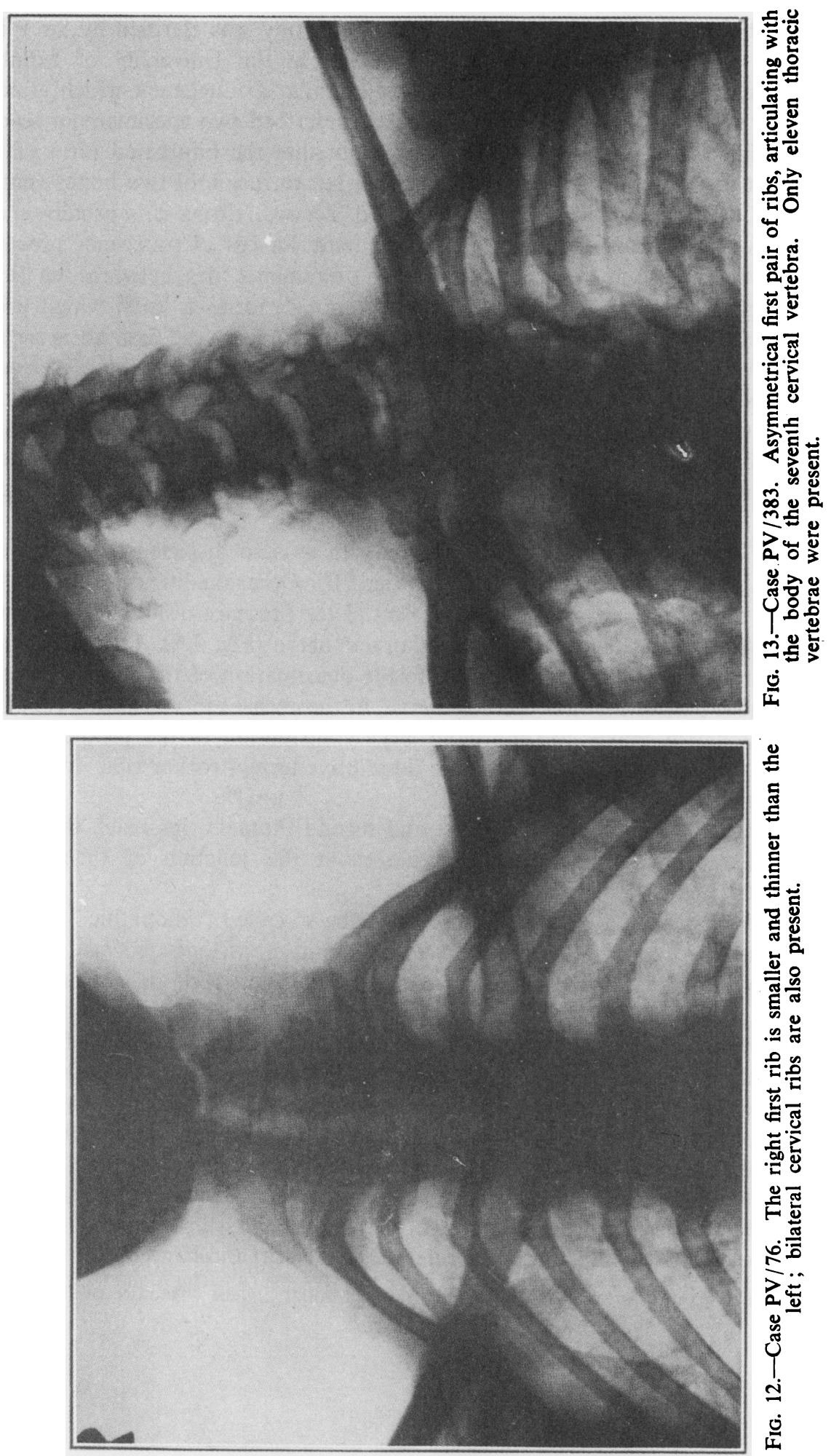
ribs ; the true embryological origin of the deformity was clarified by Sir William Turner while he was Professor of Anatomy in the University of Edinburgh (Turner, 1871). Turner drew attention to a similar arrangement which is normal for the first two ribs in the whale ; and he described two specimens of so-called "bicipital rib" (Fig. 6A and B, pointing out that the bifurcated form of rib is due not to the subdivision of a single bone, but to fusion of two bones ventrally.

2. Cervical rib.-The least "degree" of cervical rib as it is usually encountered is enlargement of the costal element (anterior bar of transverse process) of the seventh cervical vertebra. This bony prominence lies between the seventh and eighth cervical roots, and when large enough forms a knob which projects between these roots. The seventh root descends to cross the first rib in a groove immediately ventral to its angle; the eighth reaches the rib at the posterior part of the sulcus nervi brachialis. Very rarely a second cervical rib may be attached to the sixth cervical vertebra, even underlying the subclavian artery; in one of the recorded cases, the radial pulse disappeared when the subject inspired deeply.

Cervical ribs are not necessarily associated with prefixation of the brachial plexus.

3. First rib.-The normal first rib has an axis so disposed that the rib will rest on a flat surface at every point (Fig. 7B). Occasionally its axis is changed the rib forming a very broad $\mathrm{V}$ as a result of the presence of a bend in the neighbourhood of the sulcus for the first thoracic nerve (Fig. 7A). This configuration was ascribed by Wood Jones (1910) to the deformation of the developing rib by the caudal pull of the first thoracic nerve, in those cases in which this root of the brachial plexus makes an unusually large contribution to the plexus (postfixed plexus). To first ribs of this type the descriptive term " rocker ribs" was applied by Wingate Todd (1912).

Occasionally, although both first and second thoracic ribs reach the sternum, they also articulate through bony bosses at the junction of their primitive elements (Fig. 8).

There has been a renewal of interest in the so-called "idiopathic" fracture of the first rib. Lane drew attention to the condition so long ago as 1885 ; more recently Alderson (1944) found 64 cases in 81,682 men of the Royal Navy. In only eight cases was there a history of trauma ; and it may be supposed that some of the other cases represent congenital abnormalities, possibly of the nature of failure of union between the pleurapophysis and the haemapophysis (Fig. 9). However, according to Alderson, the situation of the loss of continuity in the rib is usually ventral to the line of fusion of the two elements of the rib ; in some cases serial radiological examination has shown evidence of healing. Moreover, the " fracture" is often unilateral, and osseous developmental anomalies are notoriously bilateral. A unilateral example of this lesion is shown in Fig. 10 ; in this case the patient's complaints were referred to the arm and hand on the same side.*

*During the discussion of this paper the occasional " silent" fracture of the remaining first rib after thoracoplasty was reported. 
Apart from these more obvious abnormalities, the first ribs may not be symmetrical, one rib being smaller and thinner than the other (Fig. 11). In two cases in my own series, this asymmetry was associated with the presence of cervical ribs also (Fig. 12). In another patient, although twelve pairs of ribs were present, there were only eleven thoracic vertebrae, the most cranial pair of ribs articulating with the seventh cervical vertebra (Fig. 13).

4. Scoliosis.-Scoliosis at the level of the thoracic outlet may occur either when the vertebral bodies are present (Fig. 13), or when a half-vertebra is absent, the latter condition being associated with absence of the corresponding rib. Both these types of scoliosis give rise to asymmetry of the thoracic outlet, the rib on the convex side being higher, and thrust anteriorly. In such cases the displaced rib may impinge on the neuro-vascular bundle on its way to the upper limb. More rarely a vertebra is wedge-shaped, or an additional half-lamina may be present, and the occurrence of Sprengel's deformity and of the Klippel-Feil syndrome has been recorded.

\section{Muscular Anomalies}

1. Of the scalenus anterior.-The scalenus anterior arises by tendinous slips from the anterior tubercles of the transverse processes of the third, fourth, fifth, and sixth cervical vertebrae. In their passage laterally and downwards towards their common insertion into the tubercle of the first rib, these slips pass anterior

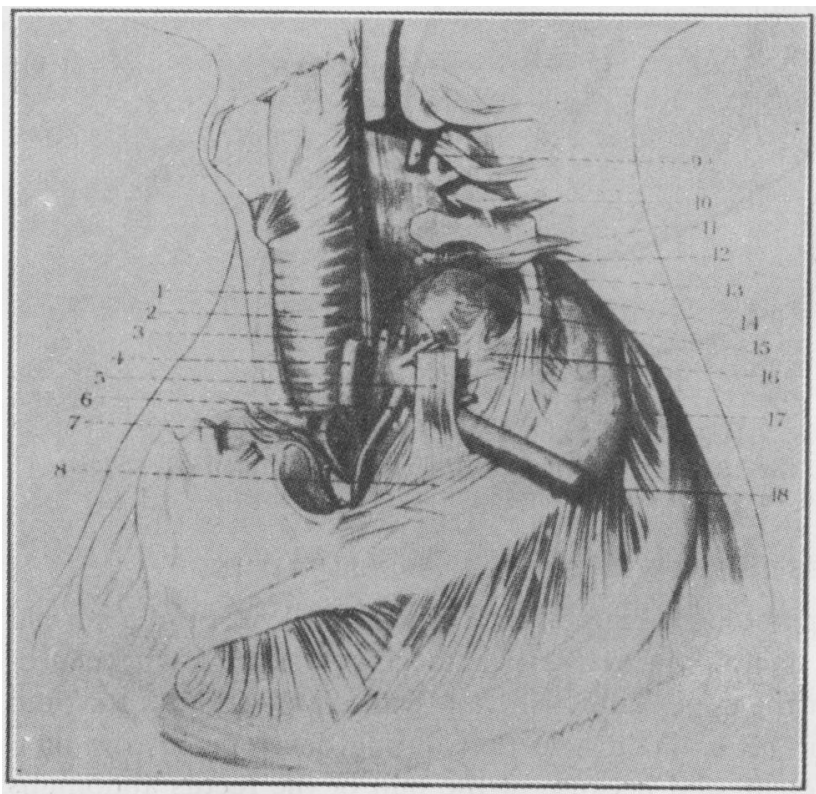

Fig. 14.-To show cleft between scalenus anterior (5), cervical rib (14) and first rib (17) (Dow). (By kind permission of Prof. D. Rutherford Dow and the Editorial Committee of the Journal of Anatomy.) to the cervical nerves as they lie in the grooves on the transverse processes: thus they are in relation to the fifth, sixth, and seventh cervical nerves contributing to the brachial plexus. Deep to the insertion of the scalenus anterior are the second part of the subclavian artery and the cords of the brachial plexus, lying in a V-shaped interval, one limb of which is the muscle, the other limb the first rib, or it may be a cervical rib ; occasionally the nerves emerge between segments of the muscle as 
in a case of my own. In this cleft the neuro-vascular structures may be compressed, when it is narrowed by the addition of a cervical rib (Fig. 14), when the first rib is oblique, or when (but this is less certain) the scalenus anterior muscle is hypertrophied. The cleft may be narrowed by hyperextension of the neck, and by faradic stimulation of the muscle; the "pincers" may be relaxed by paralysing the muscle by injections of procaine solution.

2. Of the scalenus pleuralis.- This inconstant muscle arises from the anterior tubercle of the transverse process of the seventh cervical vertebra, and is inserted into the inner border of the first rib and the fascia supporting the pleura. It may be represented by a fibrous strand, the ligamentum costopleurovertebrale (Fig. 15), and this band may compress the lowest root of the brachial plexus (the first or first and second thoracic nerves), especially when the first rib is abnormal.

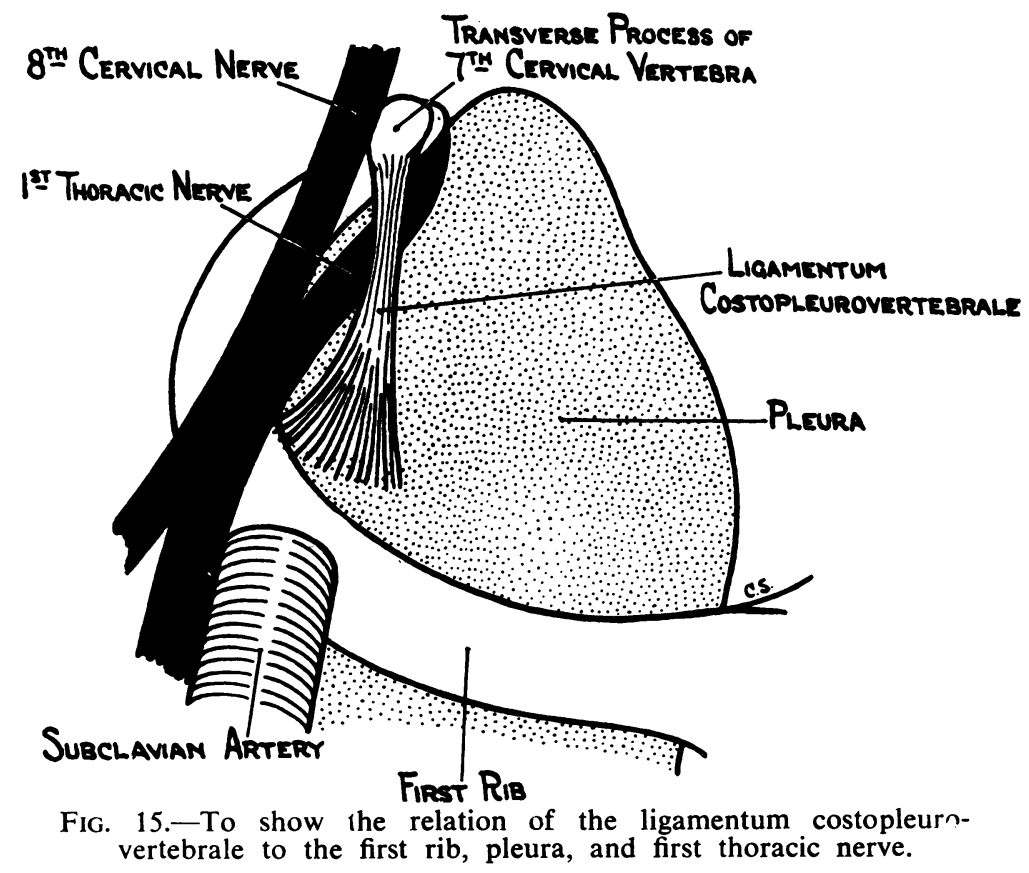

\section{Combined Osseous and Muscular Abnormalities}

Obviously the potential pathological importance of a cervical rib, or of a normal or abnormal first rib, as a factor in contributing to compression of the neurovascular bundle destined for the upper limb, will vary with the position of the limb and its girdle relative to the neck. Todd held that during development the limb descended because of its weight, and because of the pull of the rectus abdominis muscle transmitted through the sternum (Weddell, 1945). The degree of descent is partly controlled by the suspensory muscles of the limb-girdle (trapezius, etc.), and is the greater the poorer the development of these muscles. This is seen in 
women (Figs. 16 and 17) and in poorly developed men with sloping shoulders ; cervical ribs may also be present (Fig. 17). Moreover, the suspensory muscles, originally adequate for their task, may be overcome by being called upon for efforts beyond their capacity (weight-carrying), especially if these are continued, or may be weakened by long illnesses; the upper limb will then descend further.

1. Unusually high first rib.-In the light of the preceding paragraph, it is clear that the "highness" of the rib is often relative ; but in certain cases the rib lacks its usual slope downwards and anteriorly, when the highness may be absolute.

2. Costo-clavicular compression.-It has recently been emphasized (Falconer and Weddell, 1943) that the subclavian artery and vein may be compressed between the clavicle and the first rib, when the clavicle is forced downwards and backwards as happens when a soldier stands rigidly to attention, or when he wears a heavy pack ; in such cases the interval between the clavicle and the first rib is smaller than usual. This abnormality is not necessarily associated with poor muscular development: I have observed it in a sturdily built man.

In this category there must be included those cases in which massive formation of callus after fracture of the clavicle so narrows the costo-clavicular interval that there is constant pressure upon the subclavian vessels, or that slight changes in posture are sufficient to produce such pressure. In my view, the condition is so uncommon that it is probably associated with pre-existing reduction of the costoclavicular interval.

\section{Clinical Features}

There is much to be said in favour of the proposal of Walshe, Jackson, and Wyburn-Mason (1944) that "there are really only two categories in question: (i) those associated with an abnormal upper thoracic outlet, and (ii) those associated with a normal thoracic outlet, but with an altered topographical relationship between this and the shoulder girdle." Both these sets of circumstances may lead to compression of the neuro-vascular bundle on its way to the upper limb. In general, it might be expected that this process would be a gradual one, the determining factors being the movements of the parts in respiration, the movements of the upper limb and of the shoulder girdle, the repeated application of unusual strains upon the arm and shoulder girdle, and possibly the pulsation of the subclavian artery. In general, patients' histories support this view: thus the onset of symptoms and signs is usually deferred until early adult life (15-40, Kinneir Wilson, 1940), although extremes are encountered, ranging from 12 (Kinneir Wilson) to 68 in a patient of my own: and the progress of signs is gradual, with exceptions to which I shall refer later. Moreover, surgeons who deal with these cases are familiar with the local fibrous reaction which may ultimately develop in the vicinity of the neuro-vascular bundle, which looks like a dark red carpet over which a lawn-mower has been run, binding its elements together, and to neighbouring structures such as the pleura and the first rib ; on several occasions I have found laborious sharp dissection necessary to display 


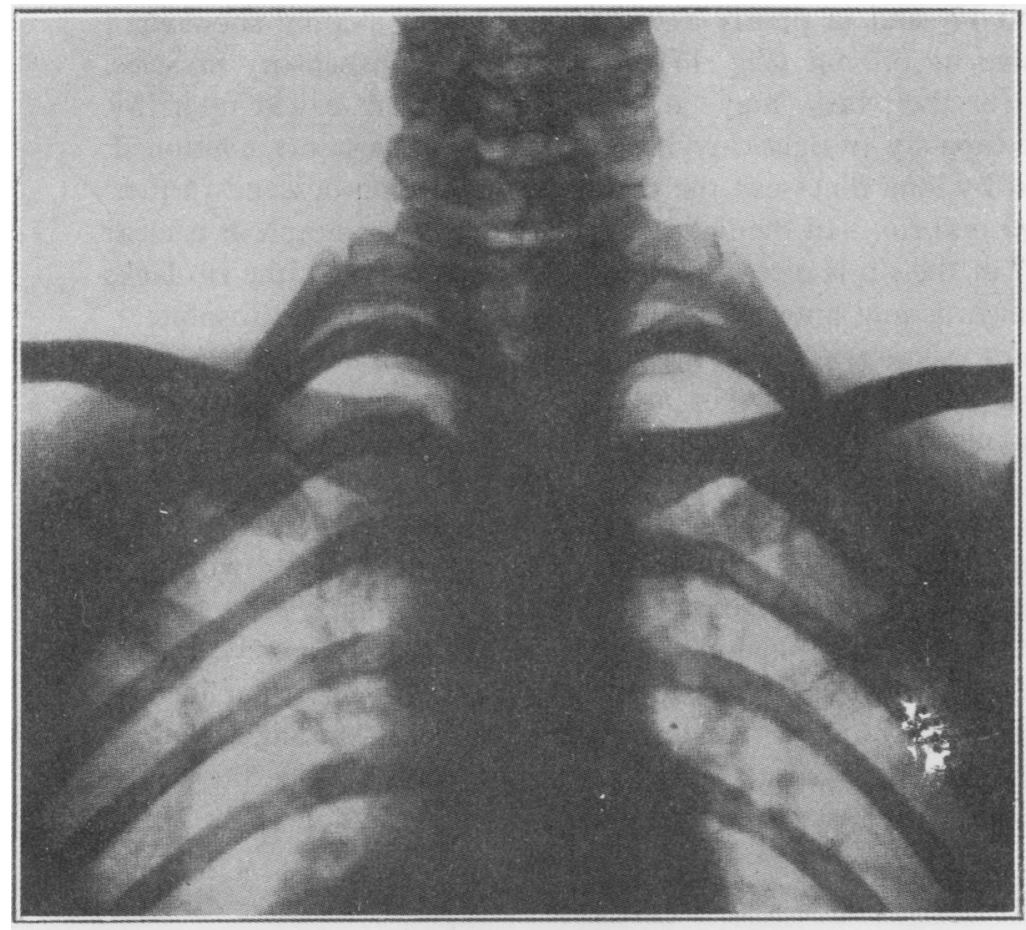

Fig. 16.-Case PV/254. To s h ow sloping sh ou lders, with " high" first rib, in a woman. Note that the medial end of the right clavicle is higher than that of the left.

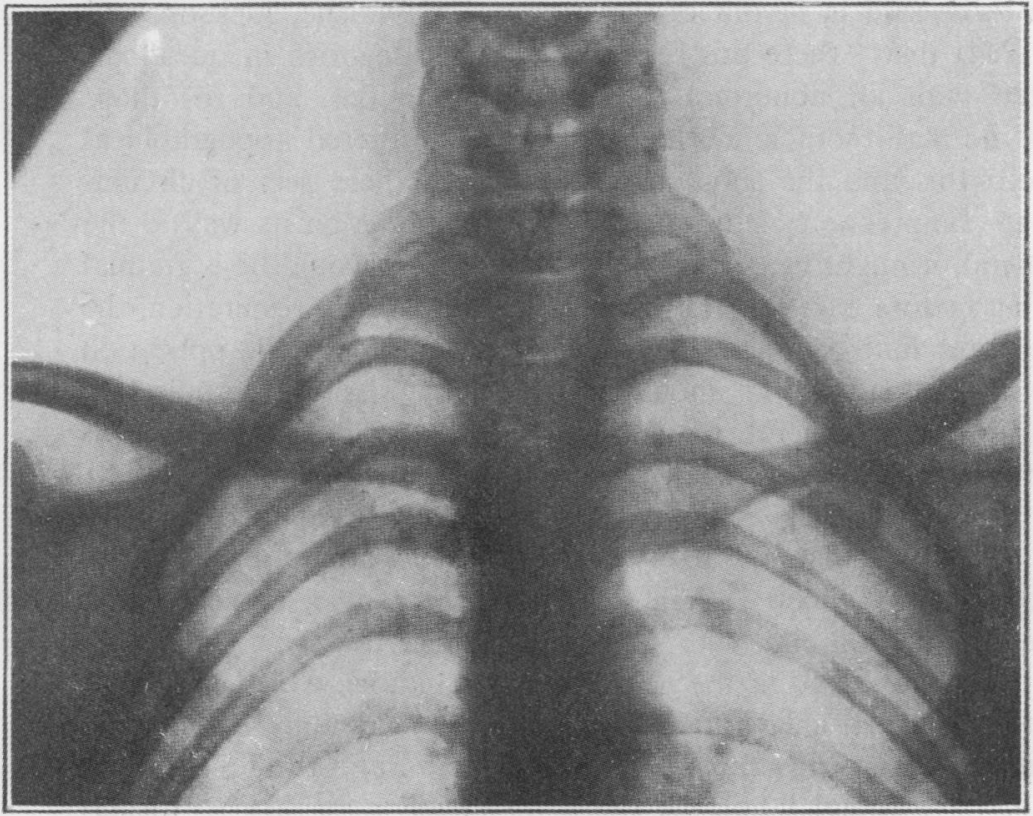

Fig. 17. - Case OL/ 142. To s h o w sloping shoulders, with " high" first rib, in a woman. Note also bilateral cervical ribs. 
the component artery and nerves. On the other hand, and possibly especially in costo-clavicular compression, symptoms and signs may appear suddenly with the adoption of an unaccustomed posture (that of "attention "); and there is a small but quite definite group of cases, of which I have encountered three examples, in which the clinical features appear in an acute manner, without, so far as can be elicited, any precipitating factor. There remains to be noted the accentuation or precipitation of vasomotor signs, when a patient is suddenly transferred from a relatively warm or mild environment to one which is much colder, a not uncommon episode during the recent war.

There is no better description of the clinical features of these cases than that given by the late Kinneir Wilson under the chapter heading "Cervical Rib," and I shall follow his arrangement. At the outset I may emphasize (as did Wilson) that symptoms and signs may both be present, or either alone.

1. Sensory features.-Although occasionally these patients complain of an ache in the neck and over the deltoid region, usually sensory features are limited to the forearm and hand, especially the latter. In the hand the fingers and their tips are particularly apt to be affected, and commonly the features are present either on the preaxial or the postaxial side of the hand. Pain may be real, or there may be paraesthesiae of a tingling character, or a feeling of numbness or of coldness. These symptoms are often relieved by elevation of the limb and its girdle, a manœuvre which many patients discover for themselves. Associated with these symptoms there may be demonstrable blunting or even loss of sensation in the territory in which pain is felt, as a rule most marked at the periphery of the digits and not necessarily coinciding with the territory of any particular cutaneous nerve. Occasionally the anaesthesia has been reported to be of the dissociated type, but my only experience of this finding was in a case in which

- well-marked cervical ribs (Fig. 17) were a complicating factor in mild syringomyelia. In cases in which vascular signs are prominent, there may be an overlay of ischaemic sensory blunting, obscuring the anatomical outlines of the defective area. This loss is acral ; it may be limited to the tips of the fingers, or be of the "finger cot" or "glove" type.

2. Motor features.-There may be slight weakness of the hand, referred to by the patient as clumsiness. In other cases muscular wasting is evident, and of this Wilson described two types: (a) wasting of the thenar eminence, limited to the muscles supplied by the median nerve and possibly associated with sensory changes on the preaxial border of the hand, and (b) wasting of the interossei, associated with the "main-en-griffe" deformity and possibly associated with sensory changes on the postaxial border of the hand. An occasional feature is the occurrence of painful cramps in the small muscles of the hand; twice I have seen these severe enough to incapacitate the hand for an hour or two at a time.

3. Vasomotor features.-These are very common, and. especially in cases in which the compression is of costo-clavicular origin, may be the only complaint. 


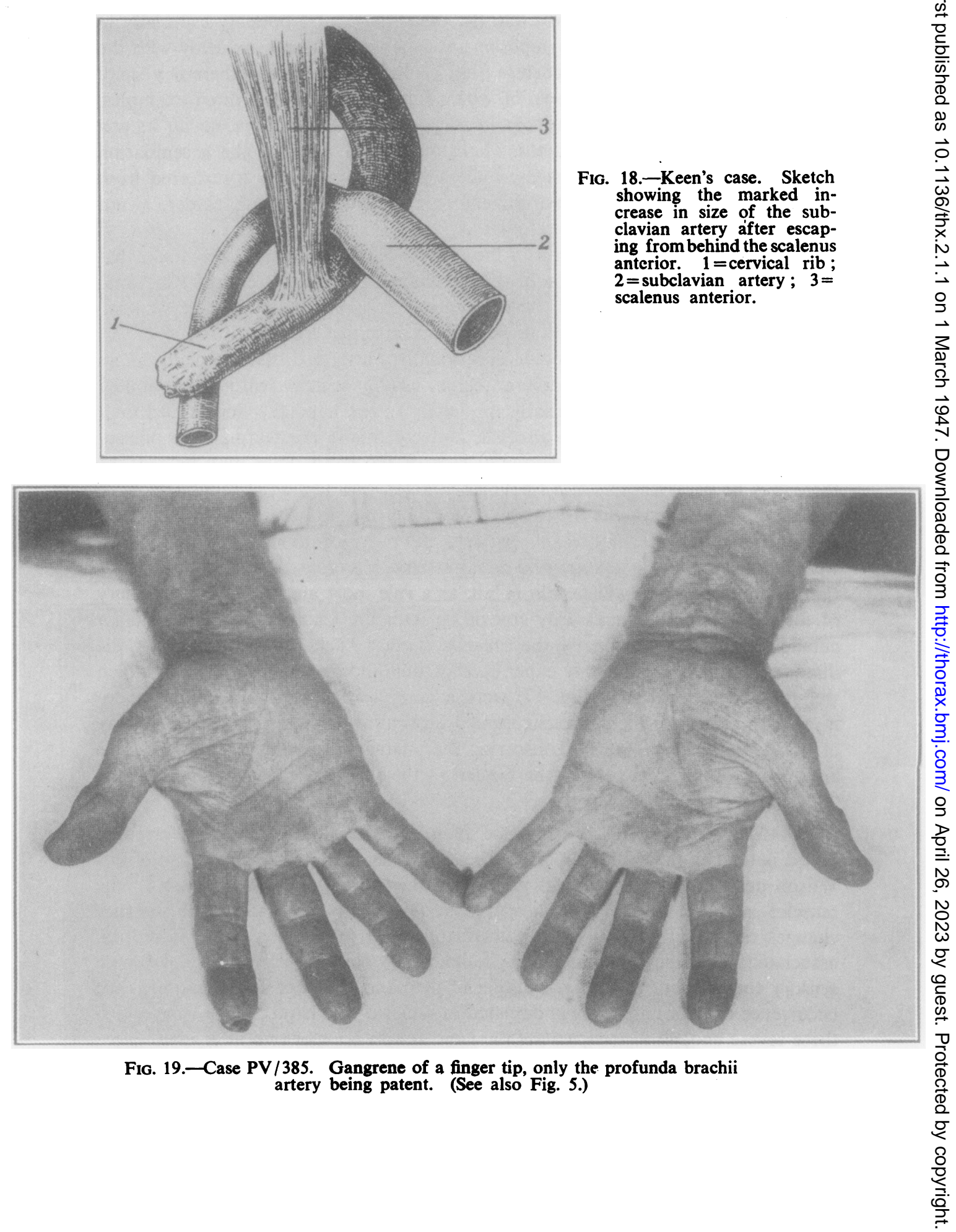


The hand and fingers may be permanently of a livid blue colour, and be cold both objectively and subjectively. In other cases there are attacks of the Raynaud phenomenon, as a rule most frequent and most severe in cold weather, but occasionally occurring in warm weather. When the subclavian artery is shut off by costo-clavicular compression, as by standing at attention, the arm may rapidly become cold, numb, and ultimately powerless, so that on parade a soldier may allow his rifle to slip from his grasp. An interesting finding in this group is that, although the wearing of a heavy pack may lead to the same sequence of events when a soldier is at attention, when he is on the march, and swinging his arms freely, disability may not occur.

Of especial interest to me has been the dilatation of the subclavian artery in its third part which is apparent in certain cases and which was discussed by Keen (1907) (Fig. 18). Whether a cervical rib be present or not, this is probably due to a measure of costo-clavicular compression. It has been ascribed to interruption of the vasa vasorum, with consequent weakening of the wall of the artery, but in two cases I have satisfied myself, by dissecting off a portion of the adventitia, that these vessels were present and patent. There is no doubt that mural thrombi may form in the dilated artery, which later becomes detached to block the digital arteries with production of gangrene at a finger tip (Fig. 19), or an intractable paronychia. I have seen four cases showing dilatation of the third part of the subclavian artery. In one, thrombi had not been detached (Fig. 20). In one the subclavian artery was completely thrombosed, the proximal level of the process reaching the lateral borde. of the scalenus anterior ; the second part of the artery pulsated, an observation disposing of the hypothesis that direct pressure of the scalenus anterior muscle was a factor in the production of the thrombus. In one in which the first rib had been removed elsewhere, the axillary artery was thrombosed, the subclavian patent. In the fourth case the sequence of events appeared to have been plugging of the digital arteries of the thumb and index finger, followed by gradual extension of the thrombus to the radial artery, which I divided between ligatures where it was patent. When the patient-a man aged 68-again came under my care, the ulnar artery was also thrombosed, and the brachial as high as, approximately, the origin of its profunda branch ; eventually the third part of the subclavian artery ceased to pulsate. Even with this extensive obliteration of the main arterial trunks, gangrene was limited to the original loss of the pulp of the index finger, the collateral circulation being adequate for the nutrition of the remaining tissues (Fig. 19).

In those cases in which pressure upon the subclavian artery is continuous, the blood pressure is reduced and the pulse is of smaller volume on the affected side. When thrombosis has blocked the third part of the artery, in my experience the radial pulse is absent. Naturally the bulk of the muscles of the arm is reduced by the relative ischaemia. 


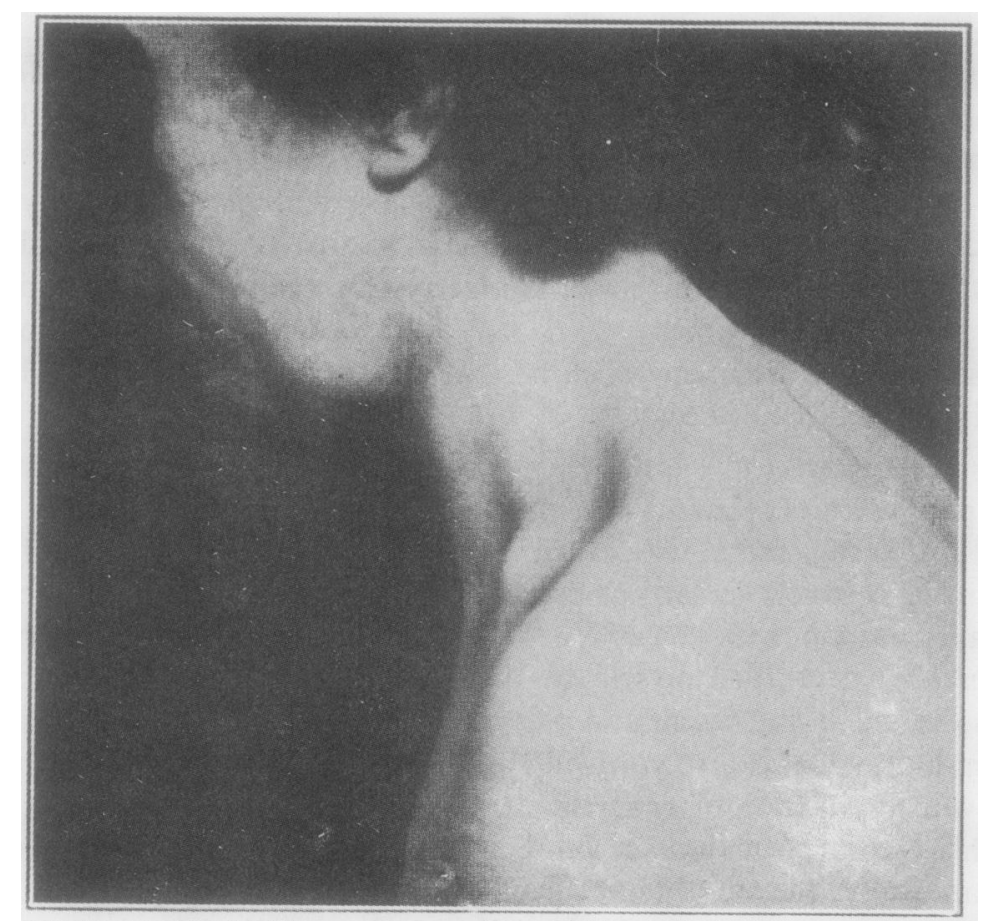

FIG. 20.-Case PV/383. To show dilatation of third part of subclavian artery in a case of "cervical rib."

Cases of costo-clavicular compression occur in which obstruction to the return of blood in the subclavian vein is a significant feature; the subcutaneous veins over the pectoral region are dilated, and there may be swelling of the hand, either permanent or fluctuating in degree. The site of the obstruction between the clavicle and first rib may be demonstrated, if it is desired, by venography.

I believe that the various vasomotor phenomena that may occur in cases of abnormality at the thoracic outlet can be explained as the result of mechanical pressure on the subclavian vessels, and that pressure upon vasomotor nerves in the brachial plexus is not a factor in their production. However, in one patient (Case PV/383) I have seen vasomotor instability persist after removal of an abnormal rib, which articulated with the seventh cervical vertebra, and was the uppermost of twelve ribs (Figs. 13 and 20). Strong downward and backward bracing of the shoulders continued to obliterate the pulse, the clavicle being forced against the second rib. But in addition the hand remained extremely coldsensitive, and Raynaud attacks could be precipitated at once, by a draught of cold air, quite irrespective of the position of the arm and shoulder girdle; this complication disappeared after cervico-dorsal preganglionic sympathectomy.

Cases have been described in which there was evidence of sympathetic paralysis, including Horner's syndrome, pointing to involvement of the stellate 


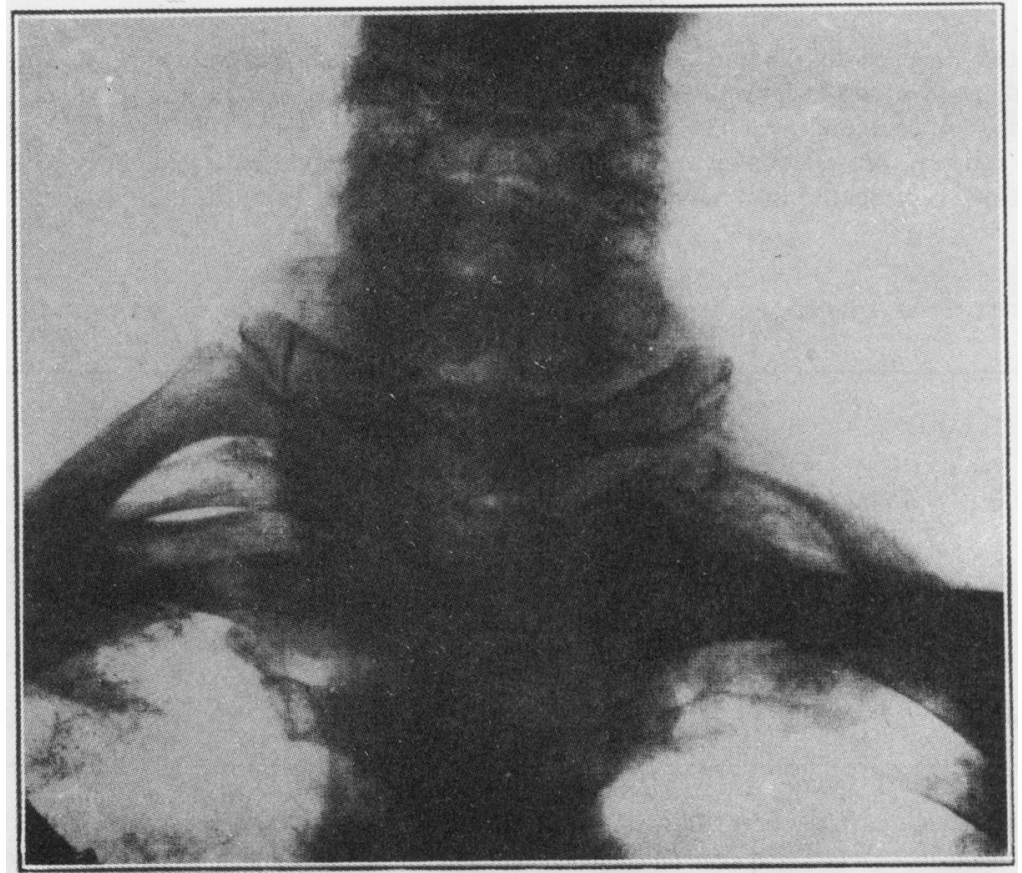

FIG. 21.-Case OL/177. "Superior pulmonary sulcus" tumour, with involvement of the transverse process of the seventh cervical vertebra and the first and second ribs on the left side. An axillary gland removed for biopsy showed a metastatic deposit of a papillary carcinoma suggested to be either of thyroid or of brachial origin.

ganglion. The mechanism of production of this paralysis is obscure: I have not encountered such a case: when sympathetic paralysis is associated with muscular weakness and wasting, and with pain about the shoulder and possibly sensory impairment over the medial aspect of the forearm and hand, the presence of a so-called "superior pulmonary sulcus tumour" should be suspected (Fig. 21).

\section{DiAgNOSIS}

Complaint of sensory, motor, or vasomotor symptoms such as have been discussed in the preceding paragraphs demands the recording of a detailed history, in which the mode of onset and progress of the condition are set out. This is followed by a careful clinical examination, which should include palpation of the root of the neck; a neurological examination to determine the presence and extent of sensory loss and of motor weakness ; an estimation of the temperature of the affected hand and a note of any peculiarity of sweating confined to it. There remain two ancillary methods, namely postural tests and radiography. 


\section{Postural Tests}

The two most useful postural tests are backward and downward bracing of the shoulders, which reduces the costo-clavicular interval, and hyperextension of the neck, which tautens the scalenus anterior muscle. The results of these manouvres upon 100 "normal" persons, picked at random, are set out in Table II, which contains the data collected by Falconer and Weddell (1943), presented in a way slightly different from the Table in their paper.

TABLE II

EFFECT OF FORCED POSTURES ON THE RADIAL PULSES OF NORMAL PERSONS (50 MEN, 50 WOMEN)

\begin{tabular}{|c|c|c|c|c|c|c|}
\hline \multirow{3}{*}{ Result of manœuvre } & \multicolumn{6}{|c|}{ Percentage affected } \\
\hline & \multicolumn{2}{|c|}{$\begin{array}{l}\text { Backward and downward } \\
\text { bracing of shoulders }\end{array}$} & \multicolumn{2}{|c|}{$\begin{array}{l}\text { Hyperextension } \\
\text { of neck }\end{array}$} & \multicolumn{2}{|c|}{$\begin{array}{c}\text { Either } \\
\text { manceuvre }\end{array}$} \\
\hline & Men & Women & Men & Women & Men & Women \\
\hline 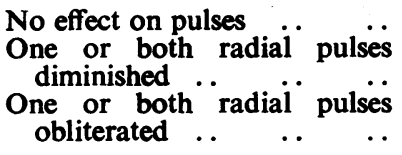 & $\begin{array}{l}50 \\
14\end{array}$ & $\begin{array}{l}42 \\
22\end{array}$ & $\begin{array}{r}82 \\
2\end{array}$ & 14 & 14 & $\begin{array}{l}40 \\
22\end{array}$ \\
\hline
\end{tabular}

Although in civil practice cases of pathological abnormality of the thoracic outlet are more common in women than in men, this selectivity is not apparent when clinical features are absent. Nevertheless backward and downward bracing of the shoulders is the best test for narrowness of the costo-clavicular interval, the radial pulse (or radial pulses) disappearing when this abnormality is the principal factor in the production of symptoms and signs. On the other hand, the main result of hyperextension of the neck is to tauten the scalenus anterior muscle, although it may narrow the costo-clavicular interval by elevating the first rib. Neither test is conclusive, and any result must be considered in the light of the remainder of the clinical picture.

\section{RADIOGRAPHY}

Radiographs of the root of the neck will reveal bony abnormalities, and may indicate the diagnosis when the individual bones are normal, but the relationship of shoulder-girdle and arm to trunk is abnormal; the various possibilities have been described. Fibrous segments of abnormal ribs and fibrous bands are not visible in radiographs. When an abnormal rib is present its position must be accurately identified by including in the plates a length of the vertebral column sufficient for counting either the cervical or thoracic vertebrae, or both. When abnormality of a vertebral body is discovered, stereoscopic plates may be needed for exact diagnosis. The necessity for accurate radiological evidence has often been stressed, but does not seem to be sufficiently recognized: a pertinent example is shown in Fig. 13.

\section{Treatment}

Treatment may be either conservative or operative.

1. Conservative treatment.-Conservative treatment may be chosen when symptoms are mild and signs are absent or minimal and when there is a precipitating factor which can be dealt with (the carrying of weights, weakness of the 
shoulder muscles after illness, standing at attention, or carrying a heavy pack). Some of my Service cases, whose disability dated from their enrolment, remained useful in types of military employment in which they could be excused parades and the wearing of equipment. In other cases the suspensory muscles of the shoulder girdle can be developed by exercises of the general nature of shrugging the shoulders while holding gradually increased weights in the hands. When vasomotor symptoms predominate, residence in the warmest available environment is obviously to be recommended.

In the unfortunate group of cases in which thrombosis has occurred in the subclavian artery, and emboli have lodged in the digital arteries, $I$ have been unable to persuade myself that operative interference is worth while. Minor amputations may be required, and advice on choice of work and on protection of the hand from cold and from trivial injuries.

2. Operative treatment.-The presence of neurological signs is an indication for operation, and the earlier it is performed the more complete the return of motor power and of sensory acuity. Operation is indicated also when vasomotor signs interfere with work or with recreation. If doubt remains as to the exact mechanism producing the clinical features, the point can be settled by exposure of the parts under local anaesthesia, the patient being instructed in turn to hyperextend the neck, and to brace back the shoulder, while the relations of the structures are studied, and the effect upon the subclavian artery and the radial pulse noted; if general anaesthesia is used, the movements may be carried out passively. When the third part of the subclavian artery is prominently dilated, costo-clavicular compression is present.

The exposure may be by a supraclavicular incision. I do not think it is necessary to divide the clavicular head of the sternomastoid. If the scalenus anterior muscle is not a factor in the production of compression, it should not be divided, because this allows the first rib to sink downwards and aggravates any costo-clavicular narrowness, as I have found to my chagrin. Careful search must be made for any fibrous bands, especially for a ligamentum costopleurovertebrale descending between the subclavian artery and the first thoracic nerve and impinging on the latter. Any constricting muscular or aponeurotic structure should be carefully divided on a director; if the scalenus muscle is to be divided, the phrenic nerve must first be isolated and protected. When the neuro-vascular bundle is bound down by fibrous tissue I believe that its component parts should be separated by sharp dissection, and as much as possible of the fibrous tissue removed. If a cervical rib encroaches on the neuro-vascular bundle it should be removed, and if it articulates with the first rib the upper surface of the latter should be smoothed by gouge forceps. During these steps only the most gentle retraction of the subclavian artery and of the brachial plexus should be permitted. Drainage is not necessary.

There is much to be said for removing an obstructing first rib through the posterior approach familiar to this Society. I have combined removal of the rib, I believe with additional benefit, with section of the thoracic sympathetic chain below the second ganglion, division of the rami communicantes of that ganglion, and implantation of the cranial end of the chain in the vertebral muscles-a preganglionic sympathectomy of a limited type. 


\section{RESULTS}

I have not had any death after any of these operations. Convalescence has been, as a rule, smooth and speedy. With one exception the patients have been satisfied with the results of operation, but I cannot be definite on this point, because in most cases it has not been possible to keep them under observation over a sufficiently long period. The exception was a patient in whom I mistook the site of obstruction. The real lesion was costo-clavicular compression ; butagainst the opinion of my junior colleagues-I performed a scalenus tenotomy. This was quite ineffective, and subsequently I removed the first thoracic rib on both sides with a successful result.

\section{REFERENCES}

Alderson, B. R. (1944). Brit. J. Radiol., 17, 323.

Dow, D. R. (1925). J. Anat., Lond., 59, 166.

Etter, L. E. (1944). Amer. J. Roentgen., 51, 359.

Falconer, M. A., and Weddell, G. (1943). Lancet, 2, 539.

Haven, H. (1939). Yale J. Biol. Med., 11, 443.

Jones, F. Wood (1910). J. Anat. Phys., 44, 377.

Keen, W. W. (1907). Amer. J. med. Sci., 133, 173.

Lane, W. A. (1885). Guy's Hosp. Rep., 43, 321.

Morris, H. (1898). "A Treatise on Human Anatomy," 2nd Edit., London: J. and A. Churchill.

Owen, R. (1866). "On the Anatomy of Vertebrates," Vol. 1, London: Longmans. Green and Co.

Struthers, J. (1875). J. Anat. Phys., 9, 17.

Sycamore, L. K. (1944). Amer. J. Roentgen., 51, 593.

Todd, T. Wingate (1912). Anat. Anz., 41, 257.

Turner, W. (1871). J. Anat. Phys., 5, 348.

Walshe, F. M. R., Jackson, H., and Wyburn-Mason, R. (1944). Brain, 67, 141.

Weddell, G. (1945). Proc. roy. Soc. Med., 38, 601 .

White, J. C., Poppel, M. H., and Adams, R. (1945). Surg. Gynec. Obstet., 81, 643.

Wilson, S. A. Kinneir (1940). "Neurology," Vol. 2, London: Edward Arnold and Co. 